\title{
Vapour phase transport of ethanol- and butanol-blended gasoline compounds in the vadose zone: a lysimeter experiment
}

\author{
Ejikeme Ugwoha
}

Received: 25 December 2013/Accepted: 29 March 2014/Published online: 25 April 2014

(C) The Author(s) 2014. This article is published with open access at Springerlink.com

\begin{abstract}
Lysimeter experiments were conducted to compare the vapour phase transport of $20 \%$ ethanol- and butanol-blended gasoline (E20 and B20) compounds in soils using the unblended gasoline (UG) compounds as the standard. Sand containing approximately 0 and $5 \%$ organic matter $\left(0 \% \mathrm{f}_{\mathrm{om}}\right.$ and $\left.5 \% \mathrm{f}_{\mathrm{om}}\right)$ was used to simulate the vadose zone. The $5 \% \mathrm{f}_{\mathrm{om}}$ soil promoted higher vapour phase transport of compounds than the $0 \% \mathrm{f}_{\mathrm{om}}$ soil due to its higher porosity, hence, was used to compare the transport to the groundwater zone of the different gasoline blends. The addition of $20 \%$ alcohol by volume to gasoline reduced the retentive capability of the soil for gasoline compound vapours and thus resulted in greater downward transport and higher accumulation of gasoline compounds in the groundwater zone. The transport of gasoline compounds from the vadose zone to the groundwater zone was found to be in the order of E20 > B20 > UG, indicating that the risk of groundwater contamination with gasoline compounds after a spill or leak is more likely to be greater for ethanolblended gasoline compared with butanol-blended gasoline.
\end{abstract}

Keywords Lysimeter - Ethanol-blended gasoline · Butanol-blended gasoline - Vapour phase transport . Groundwater contamination

\section{Introduction}

Alcohol-blended gasoline is widely used as fuel and its release into the environment is likely. After an accidental

E. Ugwoha $(\bowtie)$

Chemical and Environmental Engineering, University of

Nottingham, Nottingham NG7 2RD, UK

e-mail: ugwohaej@yahoo.com release to the soil, the transport of gasoline compounds to groundwater and the scale of contamination expected in the groundwater are problems of particular environmental concern [21]. When released to the soil, gasoline is transported in vapour and liquid phases. However, the vapour phase spreads much more efficiently than the liquid phase and can migrate towards groundwater when the liquid phase transport has stopped [26]. Consequently, the vapour phase has been extensively used in the investigation of the transport of volatile hydrocarbons in the vadose zone [4, 6$10,12,13,15,17,24]$. Although knowledge of the vapour phase transport of gasoline alone and blended with low ethanol volume (5\%) in sandy soil exist [4, 11, 17], little is known about the vapour phase transport of high volume (20\%) ethanol- or butanol-blended gasoline (E20 or B20) in the vadose zone after release. Knowing the vapour phase transport of E20 and B20 is vital as they represent future gasoline blend due to the consistent increase in alcohol volume in gasoline driven mainly by the Clean Air Act and the Energy Independence and Security Act [5, 23].

When released to the soil, either from leaks or spills, gasoline migrates downward in the vadose zone due to gravity. This is accompanied to some extent by lateral spreading due to the effect of capillary forces and medium spatial variability, with a fraction of it being retained in the pore spaces due to interfacial forces. This creates a residual saturation of gasoline that generally occupies 1-7\% of the pore space in the vadose zone [14, 19]. The transport of gasoline in the vadose zone is affected by the properties of the gasoline and porous media among other factors [14]. The presence of oxygenate, such as alcohol, can potentially change two properties that control the fate of gasoline in the vadose zone [18, 19]. Firstly, the partitioning of the gasoline is increased, leading to an increased flux of the gasoline compounds to the groundwater. Secondly, the 
surface and interfacial tensions that cause interfacial forces, which result in entrapment of residual gasoline in the vadose zone, are reduced, leading to less capillary entrapment. According to Powers and co-workers, these changes occur due to the differences in the hydrophobicity of alcohol relative to gasoline compounds. Thus, since the hydrophobicity of ethanol is relatively different from that of butanol, their individual impact on the transport of gasoline in the vadose zone could be different. Knowing the difference is vital as it will provide guidance in making informed decision on which oxygenate to adopt.

Previous studies on the vapour phase transport of gasoline and gasoline blends have revealed that column experiments [7, 8, 11, 13, 24] and lysimeter experiments [4, 9, 17] have been used. However, for studies that investigated the vapour phase transport of contaminants within the vadose zone and to the underlying groundwater zone, as proposed in this study, lysimeters were employed [4, 17]. The major advantages of a lysimeter over other experimental systems are that it provides direct information on the vapour phase transport of contaminants in the vadose zone and simulates the natural environment very well. The shortcomings are its gigantic size as well as the associated complexity which makes it difficult to manage and thus makes data generated from it difficult to reproduce. However, by scaling down the lysimeter to a manageable size that reduces complexity, it can be used in the laboratory to generate reproducible data which will be applicable to the field.

In this study, a scaled down lysimeter was fabricated and used to examine the vapour phase transport of ethanoland butanol-blended gasoline in soils. The soils used consisted of uncontaminated sand containing approximately 0 and $5 \%$ organic matter, referred to as $0 \% \mathrm{f}_{\mathrm{om}}$ and $5 \% \mathrm{f}_{\mathrm{om}}$, respectively. The lysimeter simulated a $28-\mathrm{cm}$-thick vadose zone above a gravel aquifer without water. Contamination involved the placement of a synthetic gasoline alone and blended with $20 \%$ ethanol or butanol, referred to as $\mathrm{UG}$, E20 and B20, respectively, on the soil surface and allowing vapour phase transports in the downward direction. The aim of the study was to investigate the difference in the transport of E20 and B20 vapours to the groundwater zone. The data obtained indicate that the risk of groundwater contamination after a spill of gasoline would be greater for E20 than B20.

\section{Materials and methods}

Fuel and soil composition

The fuels and soils used in this study have been described in a previous work [22]. Briefly, the fuels used were synthetic gasoline alone and blended with $20 \%$ ethanol or butanol, referred to as UG, E20 and B20, respectively. The synthetic gasoline was composed of the three major hydrocarbon groups in commercial gasoline, namely alkanes, cycloalkanes and aromatics. All the compounds used were of high purity $(>99.5 \%)$ and were purchased from Sigma-Aldrich chemical company, UK.

The soils used comprised a mixture of sand and peat as the soil organic matter (SOM) source. The sand contained approximately zero amount of SOM and had a particle size distribution of coarse (20\%), medium (50\%) and fine (30\%). The peat contained approximately $96 \%$ SOM in its dry state. The sand and peat were mixed to obtain soils consisting of 0 and $5 \%$ SOM by weight, referred to as $0 \% \mathrm{f}_{\mathrm{om}}$ and $5 \% \mathrm{f}_{\mathrm{om}}$, respectively. The porosities of the dry soils were 0.51 and 0.54 , for $0 \% \mathrm{f}_{\mathrm{om}}$ and $5 \% \mathrm{f}_{\mathrm{om}}$, respectively.

\section{Lysimeter experiments}

\section{Design of lysimeter}

The lysimeter used was designed to a dimension of $14 \mathrm{~cm} \times 40 \mathrm{~cm}(\mathrm{i} . \mathrm{d} \times \mathrm{h})$ and constructed using a transparent Perspex plastic tube of $0.5 \mathrm{~cm}$ thickness (Fig. 1). The $14 \mathrm{~cm} \times 40 \mathrm{~cm}$ dimension was chosen because it makes a midway size system between the systems used in the field and those used in the laboratory and can be suitably managed. Perspex was chosen because it is transparent, light, easily workable, cheap and not fragile and does not rust or react with the contaminants under investigation.

The lysimeter was equipped with eight sampling ports, one groundwater outlet tube and a lid. The sampling ports were made of stainless steel tube of $4 \mathrm{~mm} \times 21 \mathrm{~cm}$ (i.d $\times 1$ ), with $1 \mathrm{~mm}$ diameter perforations at $1 \mathrm{~cm}$ interval across the $14 \mathrm{~cm}$ length inside the Perspex plastic tube. They were strategically positioned along the lysimeter height to closely monitor the vapour phase transport of gasoline compounds within the system. Stainless steel was chosen because it does not rust or react with the contaminants under investigation and will remain perfectly horizontal at the designated position. The groundwater outlet tube was made of a Perspex tube of $4 \mathrm{~mm} \times 27 \mathrm{~cm}$ (i.d $\times 1$ ) and was positioned at the bottom of the lysimeter. Attached to the lysimeter's lid was a rain simulator made of Perspex with a $13 \mathrm{~cm}$ external diameter and $1.3 \mathrm{~cm}$ external thickness, a $10 \mathrm{~cm}$ internal diameter and $1 \mathrm{~cm}$ internal depth, with a $0.5 \mathrm{~mm}$ diameter perforations across the internal base. The lysimeter's lid and base were made of Perspex of 1.5 and $5 \mathrm{~cm}$ thickness, respectively.

\section{Lysimeter setup}

The lysimeter was setup as shown in Fig. $2 \mathrm{a}-\mathrm{c}$. A $3 \mathrm{~cm}$ depth layer of uncontaminated fine gravels, obtained from 


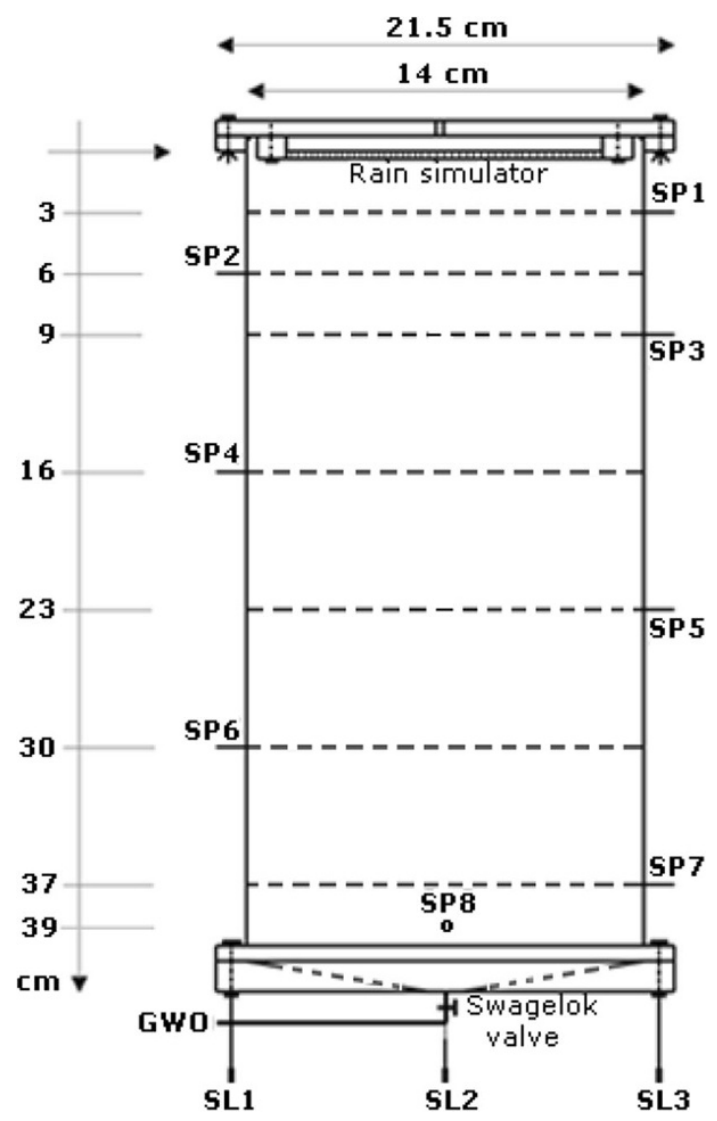

Fig. 1 A section view of the lysimeter. (SP1-SP8 are sampling ports; GWO is the groundwater outlet tube; and SL1-SL3 are supporting legs)
Nottingham (UK), was placed in the bottom and uniformly levelled (Fig. 2a). The lysimeter was then packed with dry uncontaminated $0 \% \mathrm{f}_{\mathrm{om}}$ and $5 \% \mathrm{f}_{\mathrm{om}}$ soil individually $\left(\approx 4,308.08 \mathrm{~cm}^{3}\right)$ to a height of $31 \mathrm{~cm}$ (Fig. 2b). The remaining $9 \mathrm{~cm}$ void of the lysimeter served as the headspace. The lysimeter was carefully capped and the soil wetted via the rain simulator, with 1.81 of distilled and deionised water, until water began to flow via the groundwater outlet tube aligned to the bottom of the vadose zone at exactly $28 \mathrm{~cm}$ from the soil surface (Fig. 2c). The excess water that accumulated at the bottom of the lysimeter was later drained by lowering the groundwater outlet tube, thus allowing a large number of the soil pores to be filled with gas [16]. The lysimeter was left for 2 days for the soil to stabilize and maintain residual water saturation that simulated vadose zone soil at field capacity moisture condition [15]. At the field capacity, the water retention capacities of the soils were 26 and $45 \mathrm{ml}$ for $0 \% \mathrm{f}_{\mathrm{om}}$ and $5 \% \mathrm{f}_{\mathrm{om}}$, respectively, and the volumetric water content ranged from $11 \%$ at the soil surface to $24 \%$ at the base for $0 \% \mathrm{f}_{\mathrm{om}}$ but ranged from 16 to $30 \%$ for $5 \% \mathrm{f}_{\mathrm{om}}$. No further soil wetting was performed throughout the duration of the experiment, hence, mimicking non-rainy soil condition. Consequently, the water phase in the soil was considered immobile.

Prior to contamination on the third day, the lysimeter sampling and injection ports and groundwater outlet were closed and the background concentrations of gasoline compounds in the soil gas were measured. Thereafter, the
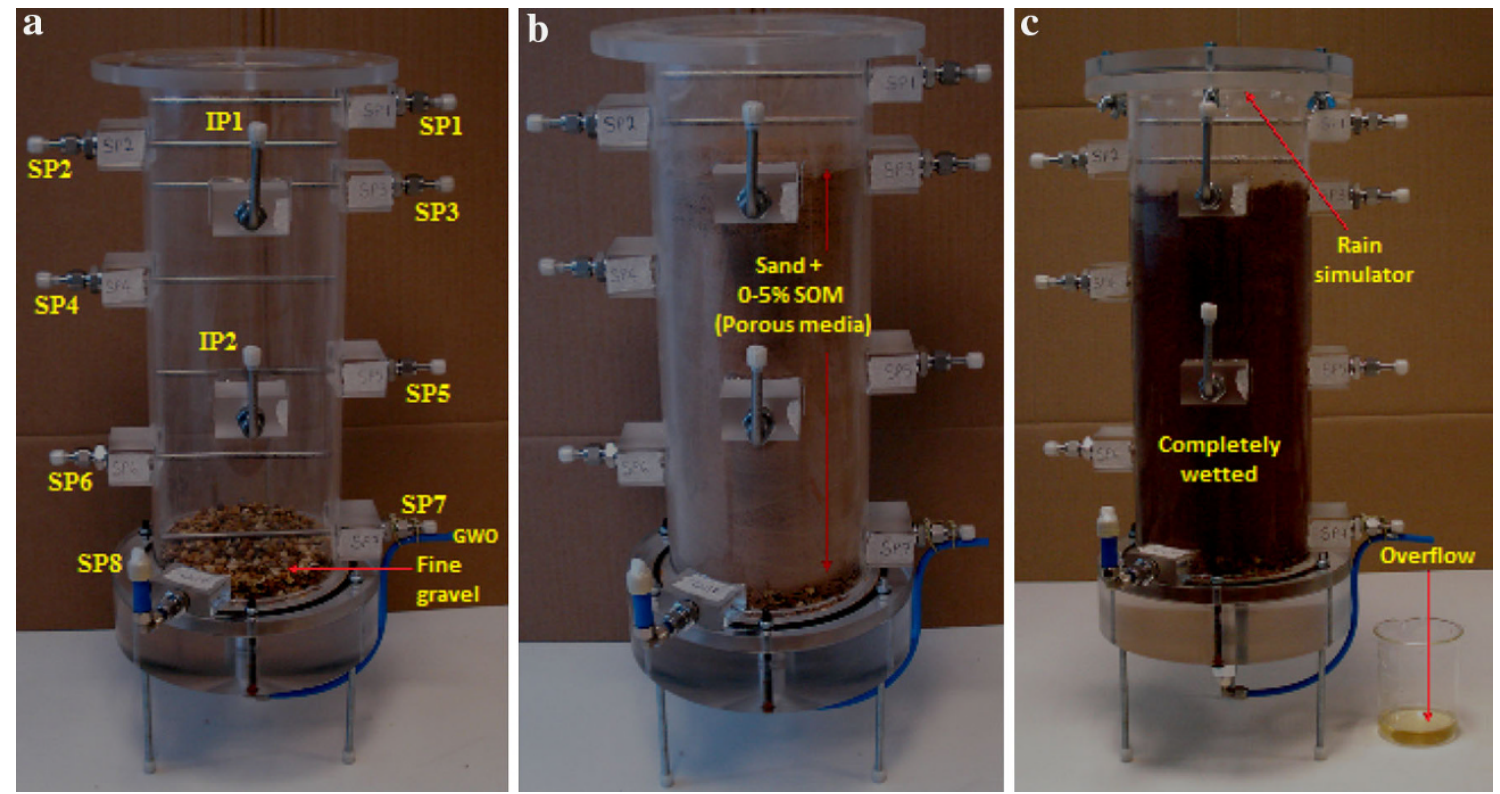

Fig. 2 Stepwise setup of lysimeter: a emplacement of uncontaminated fine gravel, b emplacement of uncontaminated dry soil, and $\mathbf{c}$ wetting of soil 
lysimeter was uncapped and $400 \mathrm{~g}$ of dry soil contaminated with $10 \mathrm{ml}$ gasoline placed on the soil surface to simulate a surface spill following the method used by Pasteris et al. [17] in their lysimeter experiment. The lysimeter was quickly capped after the placement to maintain a closed system. According to Pasteris et al. [17], the $10 \mathrm{ml}$ gasoline should fill $2 \%$ of the total porosity of the soil, which is within the $1-7 \%$ of the pore space usually occupied by gasoline residual in the vadose zone after spills [14, 19]. Hence, migration of gasoline compounds in the liquid phase (non-aqueous or dissolved phase) did not occur during this experiment. The contaminated mass of soil served as the contamination source zone. The lysimeter was maintained at a temperature of $25^{\circ} \mathrm{C}$ throughout the experiment.

\section{Soil gas sampling and analysis}

Before contamination, soil gas samples were extracted from SP3-SP7 (vadose zone) and SP8 (groundwater zone) and analysed for background concentrations of gasoline compounds. Immediately after contamination, the source zone (SP3) was sampled and analysed, and the concentration obtained was used as the initial concentration of gasoline compounds. Thereafter, soil gas samples were extracted from the source zone as well as from the other sampling ports to monitor changes in the concentrations of gasoline compounds. Soil gas samples were extracted after $4 \mathrm{~h}$ (Day 1) and daily from Days 2 to 15 . The soil gas samples were extracted and analysed by HPR-20 Mass Spectrometer (MS). The MS (Hiden Analytical, England) was equipped with Capillary, Quadrupole Mass Analyser (HAL 201-RC) and Faraday \& Secondary Electron Multiplier (SEM) Detectors and used a MASsoft version of 6.13.0.35 and a Micro board of type HAL 5. The MS was set to use the SEM Detector for faster scanning at a voltage of $850 \mathrm{~V}$. The MS scan was configured to Multiple Ion Detection (MID) to simultaneously measure compounds of different masses. Other MS settings included source

Table 1 Concentration equivalent of 1 torr of gasoline compounds for gasoline blends

\begin{tabular}{llll}
\hline Compd. & UG $(\mathrm{g} / \mathrm{ml})$ & $\mathrm{E} 20(\mathrm{~g} / \mathrm{ml})$ & B20 $(\mathrm{g} / \mathrm{ml})$ \\
\hline Pentane & $9.83 \mathrm{E}+04$ & $8.34 \mathrm{E}+04$ & $1.37 \mathrm{E}+05$ \\
Octane & $8.02 \mathrm{E}+04$ & $4.96 \mathrm{E}+04$ & $9.84 \mathrm{E}+04$ \\
$\mathrm{MCP}$ & $6.05 \mathrm{E}+04$ & $2.90 \mathrm{E}+04$ & $6.94 \mathrm{E}+04$ \\
MCH & $1.84 \mathrm{E}+05$ & $2.08 \mathrm{E}+04$ & $9.94 \mathrm{E}+04$ \\
Benzene & $2.42 \mathrm{E}+04$ & $1.44 \mathrm{E}+04$ & $3.03 \mathrm{E}+04$ \\
Toluene & $3.76 \mathrm{E}+05$ & $1.46 \mathrm{E}+05$ & $2.58 \mathrm{E}+05$ \\
Ethanol & - & $2.84 \mathrm{E}+03$ & - \\
Butanol & - & - & $8.13 \mathrm{E}+03$ \\
\hline
\end{tabular}

emission of $100 \mu \mathrm{A}$, mass range of $0.40-200 \mathrm{amu}$ at a minimum increment of $0.01 \mathrm{amu}$ and acquisition range of $10^{-8}-10^{-13}$ torr for all compounds. Soil gas samples were extracted automatically via the capillary heated up to $200{ }^{\circ} \mathrm{C}$ to improve condensable species sampling. The MS was operated at a normal vacuum pressure of $\approx 1 \times 10^{-6}$ torr. Each port was sampled for $20 \mathrm{~min}$ to obtain a stable partial pressure values. A total soil gas volume of $16 \mathrm{ml}$ was extracted per sampling time. The concentration of each gasoline compound was calculated from the average of the last three stable partial pressure values using a partial pressure-concentration relationship developed for each compound and gasoline blend during the MS calibration (Table 1).

\section{Results and discussion}

Vapour phase transport of E20

The depth profiles of the vapour phase concentrations of the E20 gasoline compounds in $0 \% \mathrm{f}_{\mathrm{om}}$ and $5 \% \mathrm{f}_{\mathrm{om}}$ soils are shown in Fig. 3. The concentration profiles are shown for only the representative compounds on Days $1,3,5,8$, 10,12 and 15 to reduce complexity. The diffusive transport of all compounds occurred from the source zone $(0 \mathrm{~cm})$ to the lower sections of the vadose zone. All compounds, except ethanol, were detected at the very low levels at the groundwater zone $(28-30 \mathrm{~cm})$ throughout the experimental duration for $0 \% \mathrm{f}_{\mathrm{om}}$. As expected for a polar compound, ethanol had a significant vapour concentration at the groundwater zone due to less interaction with the soil solids [4]. This behaviour of ethanol is not supposed to trigger any environmental concern as ethanol is highly degradable and has been reported to be completely attenuated near the source zone in a live soil lysimeter experiment [4]. On the contrary, vapours of all compounds were detected at the groundwater zone of $5 \% \mathrm{f}_{\mathrm{om}} 4 \mathrm{~h}$ after contamination on Day 1. SOM increased the porosity of the vadose zone from $40 \%$ for $0 \% \mathrm{f}_{\mathrm{om}}$ to $47 \%$ for $5 \% \mathrm{f}_{\mathrm{om}}$, hence, seemed to have promoted the vapour phase transport of compounds in $5 \% \mathrm{f}_{\mathrm{om}}$ vadose zone. For ethanol, the lower concentrations measured at the groundwater zone of $5 \% \mathrm{f}_{\text {om }}$ suggests that SOM impacted its partitioning to the soil water to a greater extent than its vapour phase transport to the groundwater zone. Similar high partitioning of ethanol to the water phase in the vadose zone and the accompanying low vapour phase transport to the groundwater has been reported [4, 13, 19]. For the gasoline compounds, SOM promoted their vapour phase transport to the groundwater zone. This effect was more visible on Days 5-15 for pentane and MCP, but only visible on Day 8 for benzene. The higher ease of partitioning to the water 
Fig. 3 Depth profiles of vapour phase concentrations of E20 gasoline compounds as a function of organic matter fraction $\left(f_{o m}\right)$ of soils
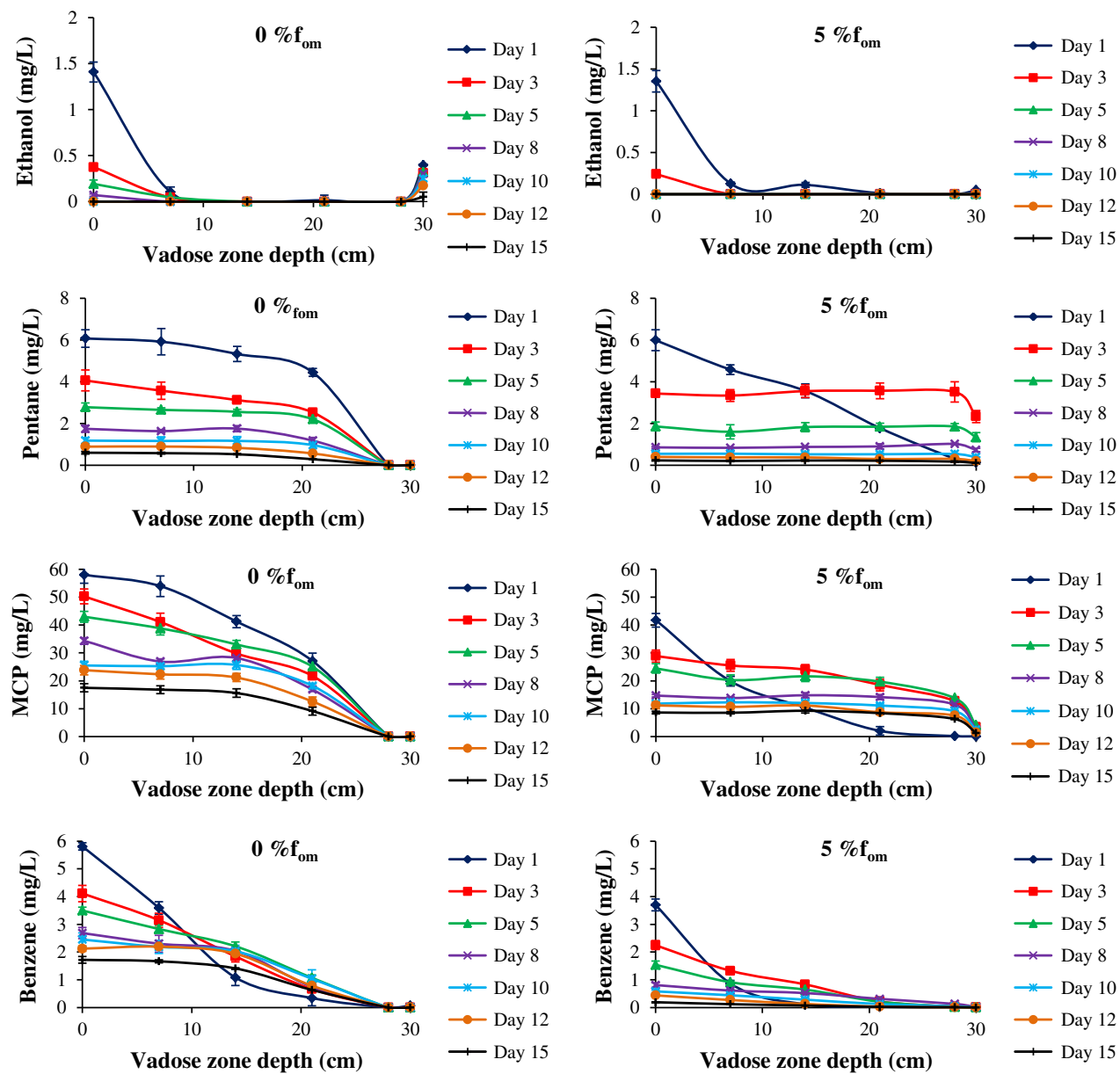

phase of benzene due to its lower hydrophobicity could be the possible reason for its insignificant change in vapour phase concentrations at the groundwater zone even with a $7 \%$ increase in the porosity of the vadose zone. Therefore, this result shows that SOM reduced the vapour phase transport of the less hydrophobic gasoline compounds to the groundwater zone by retaining more soil water in the vadose zone for partitioning, but promoted the vapour phase transport of the more hydrophobic gasoline compounds to the groundwater zone by increasing the porosity of the vadose zone.

\section{Vapour phase transport of B20}

Figure 4 shows the vapour phase concentration profiles of B20 gasoline compounds in $0 \% \mathrm{f}_{\mathrm{om}}$ and $5 \% \mathrm{f}_{\mathrm{om}}$ soils. The maximum vapour concentrations of all representative gasoline compounds were found at the source zone $(0 \mathrm{~cm})$ on Day 1. The concentrations of all compounds decreased with time due to diffusion, adsorption and partitioning. The porosity of the soil, the volatility and hydrophobicity of the compounds and the concentration of the compounds in the mixture were the dominant factors that influenced the diffusive vapour phase transport of the gasoline compounds in the vadose zone. No compounds were found at a detectable concentration at the groundwater zone for the $0 \% \mathrm{f}_{\mathrm{om}}$ soil, which had a porosity of $40 \%$, except for butanol that had the lowest hydrophobicity. This suggests that the interaction of the compounds with the soil was mainly hydrophobic interactions. In contrast, $4 \mathrm{~h}$ after contamination on Day 1 all compounds, except for benzene with the lowest concentration in the B20 mixture, were detected at the groundwater zone of the $5 \% \mathrm{f}_{\mathrm{om}}$, which had a porosity of $47 \%$. For the two soils tested, the concentration of butanol measured at the groundwater zone was higher than the other compounds, suggesting that the transport of butanol was less retarded.

Huge difference was generally observed in the behaviour of compounds in $0 \% \mathrm{f}_{\mathrm{om}}$ and $5 \% \mathrm{f}_{\mathrm{om}}$ soils. For example, butanol was above detection limit at all sections for $0 \% \mathrm{f}_{\mathrm{om}}$ soil on all days except on Day 15 . However, butanol was only above detection limit on Day 1 for the $5 \% \mathrm{f}_{\mathrm{om}}$ soil. This sudden disappearance of the butanol from the vapour phase in the vadose zone for the $5 \% \mathrm{f}_{\text {om }}$ soil was attributed to greater partitioning to the water phase due to the higher soil water retained by the $5 \% \mathrm{f}_{\mathrm{om}}$ as well as 
Fig. 4 Depth profiles of vapour phase concentrations of B20 gasoline compounds as a function of organic matter fraction $\left(f_{o m}\right)$ of soils
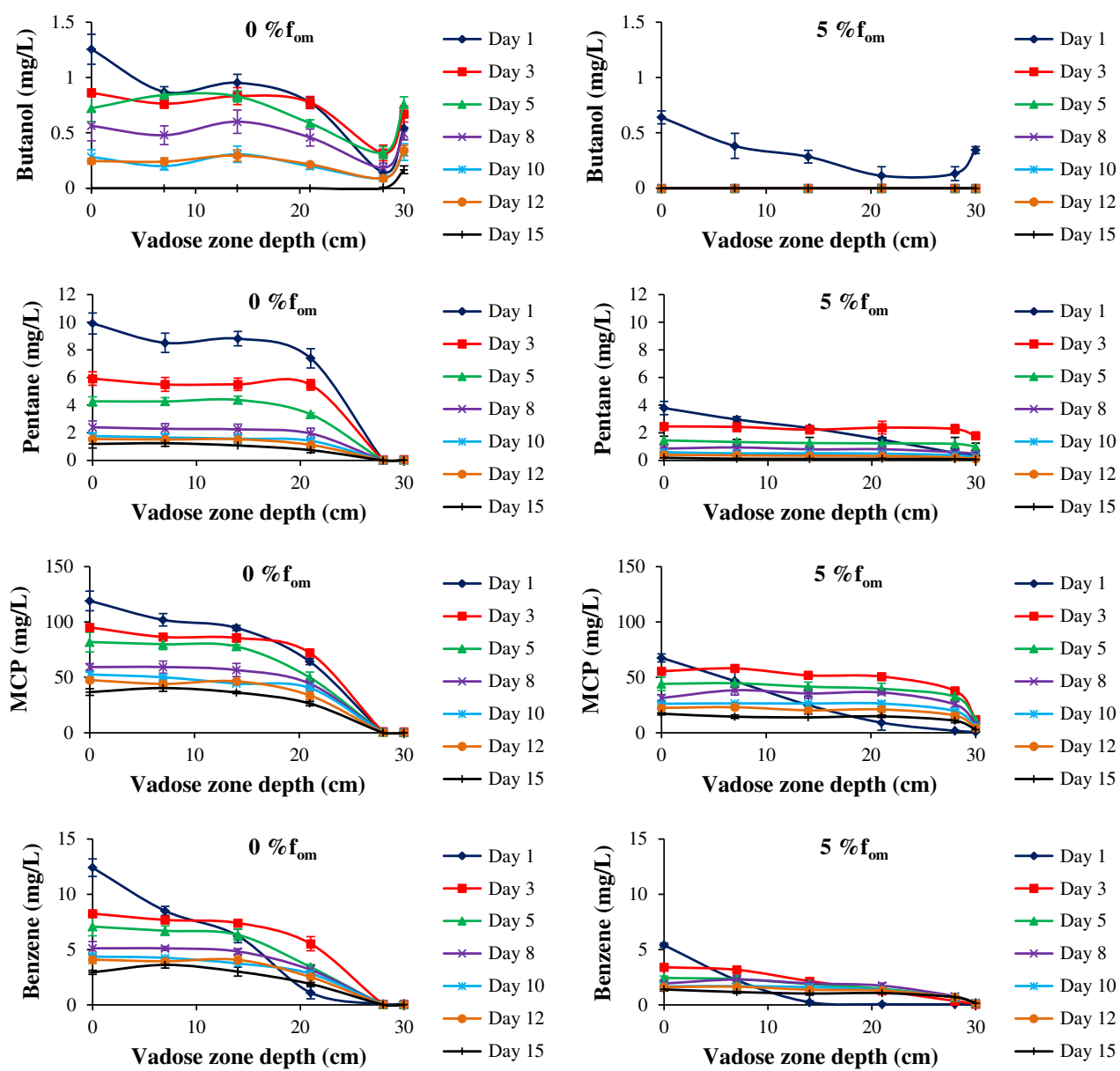

the lower vapour phase concentration measured at the groundwater zone compared with $0 \% \mathrm{f}_{\mathrm{om}}$. For the hydrophobic gasoline compounds, greater vapour phase transport to the groundwater zone was observed in the $5 \% \mathrm{f}_{\mathrm{om}}$ soil. Consequently, the concentrations of all compounds at all the soil sections were approximately halved for the $5 \% \mathrm{f}_{\mathrm{om}}$ compared with the $0 \% \mathrm{f}_{\mathrm{om}}$. The higher water absorption capacity and porosity of the $5 \% \mathrm{f}_{\text {om }}$ compared with $0 \% \mathrm{f}_{\text {om }}$ at field capacity may be the reason for the observed difference in compounds behaviour in the two soils.

Overall, the vapour phase concentrations of all compounds were drastically reduced in the $5 \% \mathrm{f}_{\mathrm{om}}$ soil compared with the $0 \% \mathrm{f}_{\text {om }}$ soil. This reduction was attributed to higher partitioning to the soil water for butanol and to greater vapour phase transport to the groundwater zone for the gasoline compounds. The difference in the $0 \% \mathrm{f}_{\mathrm{om}}$ and $5 \% \mathrm{f}_{\mathrm{om}}$ soils were attributed to variations in water absorption capacity and porosity.

Comparison of the vapour phase transport of E20 and B20 using UG as standard

Figure 5 compares the depth profiles of the vapour phase concentrations of a representative gasoline compound (pentane) on Days 1, 4, 8, 12 and 15 after contamination in the lysimeter as a function of the gasoline composition. Pentane was chosen because it is the most volatile gasoline compound, hence migrates faster, farthest and represents the worst case vapour phase transport scenario. The $5 \% \mathrm{f}_{\text {om }}$ soil was used because it promoted vapour phase transport of compounds better than the $0 \% \mathrm{f}_{\text {om }}$ soil. The vapour phase concentrations of pentane from all gasoline blends decreased with time due to adsorption on the soil solids and partitioning to the soil water. A constant rate transport of pentane from the source zone to the lower sections of the vadose zone, denoted by a horizontal concentration profile, was generally attained for all gasoline blends on Day 4. The deviation from this constant rate transport started on Day 8 for UG and B20 and on Day 12 for E20 probably due to increased adsorption on the soil solids and partitioning to the soil water.

The addition of $20 \%$ alcohol by volume to gasoline generally promoted the vapour phase concentration of pentane from Day 1 for E20 and from Day 4 for B20. It also promoted transport to the groundwater zone, however, with E20 impacted to a greater extent than B20. B20pentane displayed series of specific behaviours with time. Between Day 1 and Day 4 the B20-pentane behaved similar to the UG-pentane, but between Day 8 and Day 12 it 
Fig. 5 Vapour phase transport of pentane in $5 \% f_{\text {om }}$ soil as a function of gasoline composition
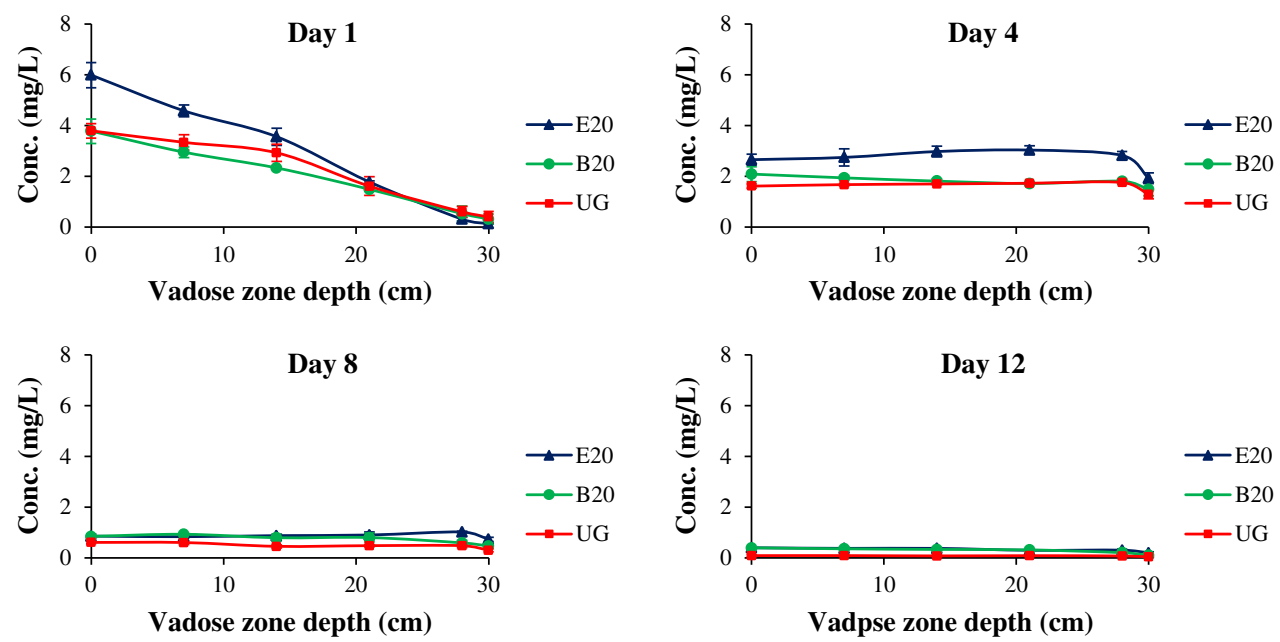

Day 15

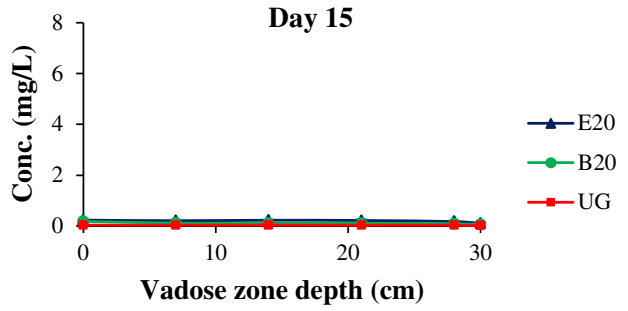

behaved more like the E20-pentane. Generally, the transport behaviour of B20-pentane was midway between E20pentane and UG-pentane. Theoretically, E20 and B20 should partitioned more into the soil water than UG due to the cosolvent effect of alcohol [1-3,20], and UG should be adsorbed more on the soil solids than B20 and E20 due to its higher hydrophobicity [25]. Therefore, the observed lower vapour phase concentration and transport for UGpentane suggests that more adsorption on the soil solids than partitioning to the soil water of pentane occurred in this study. The consistent higher vapour phase concentration of the E20-pentane in both the vadose zone and the groundwater zone indicates that E20 gasoline compounds could migrate faster and farther than B20 gasoline compounds after a spill. This implies that the E20 gasoline compounds could pose greater risk of groundwater contamination than B20 gasoline compounds. In general, Fig. 5 indicates that the transport of gasoline compounds in the vadose zone as well as the risk of groundwater contamination with gasoline compounds after a spill of gasoline is likely to be in the order of E20 > B20 > UG.

\section{Conclusions}

The vapour phase transport of E20 and B20 gasoline compounds in a simulated subsurface environment has been compared using the unblended gasoline compounds as the standard. The addition of $20 \%$ alcohol by volume to gasoline resulted in greater downward transport and higher accumulation of gasoline compound vapours in the groundwater zone. This effect was greater for E20 than B20, indicating that the use of ethanol-blended gasoline as a transportation fuel could result in greater risk of groundwater contamination with gasoline compounds after spills than the use of butanol-blended gasoline.

Acknowledgments The author is grateful to Mr. Chibuzor Ugwoha and the Niger Delta Development Commission (NDDC) of Nigeria for sponsoring this research.

Open Access This article is distributed under the terms of the Creative Commons Attribution License which permits any use, distribution, and reproduction in any medium, provided the original author(s) and the source are credited.

\section{References}

1. Adam, G., Gamoh, K., Morris, D.G., Duncan, H.: Effect of alcohol addition on the movement of petroleum hydrocarbon fuels in soil. Sci. Total Environ. 286(1-3), 15-25 (2002)

2. Chen, C.S., Lai, Y.W., Tien, C.J.: Partitioning of aromatic and oxygenated constituents into water from regular and ethanolblended gasolines. Environ. Pollut. 156(3), 988-996 (2008)

3. Corseuil, H.X., Kaipper, B.I.A., Fernandes, M.: Cosolvency effect in subsurface systems contaminated with petroleum hydrocarbons and ethanol. Water Res. 38(6), 1449-1456 (2004)

4. Dakhel, N., Pasteris, G., Werner, D., Höhener, P.: Small-volume releases of gasoline in the vadose zone: impact of the additives MTBE and ethanol on groundwater quality. Environ. Sci. Technol. 37(10), 2127-2133 (2003) 
5. EPCEU (European Parliament and Council of the European Union). Directive 2003/30/EC of the European Parliament and of the Council on the promotion of the use of biofuels or other renewable fuels for transport. In E. Union (Ed.) (Vol. L123/42): Official Journal of the European Union, L123, vol. 46 (2003)

6. Grathwohl, P.P., Klenk, I.D., Maier, U., Reckhorn, S.B.F.: Natural attenuation of volatile hydrocarbons in the unsaturated zone and shallow groundwater plumes: scenario-specific modelling and laboratory experiments. Paper presented at the groundwater quality: natural and enhanced restoration of groundwater pollution, Sheffield (2001)

7. Höhener, P., Dakhel, N., Christophersen, M., Broholm, M., Kjeldsen, P.: Biodegradation of hydrocarbons vapors: comparison of laboratory studies and field investigations in the vadose zone at the emplaced fuel source experiment, Airbase Værløse, Denmark. J. Contam. Hydrol. 88(3-4), 337-358 (2006)

8. Höhener, P., Duwig, C., Pasteris, G., Kaufmann, K., Dakhel, N., Harms, H.: Biodegradation of petroleum hydrocarbon vapors: laboratory studies on rates and kinetics in unsaturated alluvial sand. J. Contam. Hydrol. 66(1-2), 93-115 (2003)

9. Karapanagioti, H.K., Gaganis, P., Burganos, V.N., Höhener, P.: Reactive transport of volatile organic compound mixtures in the unsaturated zone: modeling and tuning with lysimeter data. Environ. Model. Softw. 19(5), 435-450 (2004)

10. Lawrence, A., Jonsson, S., Börjesson, G.: Ethanol, BTEX and microbial community interactions in E-blend contaminated soil slurry. Int. Biodeterior. Biodegrad. 63(6), 654-666 (2009)

11. Li, C., Voudrias, E.A.: Migration and sorption of jet fuel aliphatic vapors in unsaturated soil. Water Res. 28(12), 2447-2456 (1994)

12. Mariano, A.P., Tomasella, R.C., Di Martino, C., Filho, R.M., Seleghim, M.H.R., Contiero, J., de Angelis, D.d.F.: Aerobic biodegradation of butanol and gasoline blends. Biomass Bioenergy 33(9), 1175-1181 (2009)

13. McDowell, C.J., Powers, S.E.: Mechanisms affecting the infiltration and distribution of ethanol-blended gasoline in the vadose zone. Environ. Sci. Technol. 37(9), 1803-1810 (2003)

14. Meyers, R.A.: Encyclopaedia of environmental pollution and cleanup, vol. 1. Wiley, New York (1999)

15. Österreicher-Cunha, P., Vargas Jr, E.d.A., Guimarães, J.R.D., Lago, G.P., Antunes, F.d.S., da Silva, M.I.P.: Effect of ethanol on the biodegradation of gasoline in an unsaturated tropical soil. Int. Biodeterior. Biodegrad. 63(2), 208-216 (2009)

16. Page, A.L.: Method of soil analysis part 2: chemical and microbiological properties. American Society of Agronomy, Inc. and Soil Science of America, Inc., Madison (1982)

17. Pasteris, G., Werner, D., Kaufmann, K., Höhener, P.: Vapor phase transport and biodegradation of volatile fuel compounds in the unsaturated zone: a large scale lysimeter experiment. Environ. Sci. Technol. 36(1), 30-39 (2002)

18. Powers, S.E., Hunt, C.S., Heermann, S.E., Corseuil, H.X., Rice, D., Alvarez, P.P.J.J.: The transport and fate of ethanol and BTEX in groundwater contaminated by gasohol. Crit. Rev. Environ. Sci. Technol. 31, 79-123 (2001)

19. Powers S.E., McDowell C.J. Infiltration and distribution of ethanol and ethanol-blended gasoline in the vadose zone (No. UCRL-AR-145380 Ch. 2.). http://www-erd.llnl.gov/ethanol/etoh docII/ (2001)

20. Reckhorn, S.B.F., Zuquette, L.V., Grathwohl, P.: Experimental investigation of oxygenated gasoline dissolution. Environ. Eng. 127(3), 208-216 (2001)

21. Site, A.D.: Factors affecting sorption of organic compounds in natural sorbent/water systems and sorption coefficients for selected pollutants. A review. J. Phys. Chem. Ref. Data 30(1), 187-439 (2001)

22. Ugwoha, E., Andresen, J.M.: Sorption and phase distribution of ethanol and butanol blended gasoline vapours in the vadose zone after release. J. Environ. Sci. (2013). doi:10.1016/S10010742(13)60414-3

23. USEPA (United States Environmental Protection Agency). Alternative and renewable fuels (2011)

24. Wang, G., Reckhorn, S.B.F., Grathwohl, P.: Volatile organic compounds volatilization from multicomponent organic liquids and diffusion in unsaturated porous media. Vadose Zone J. 2(4), 692-701 (2003)

25. Weber Jr, W.J., McGinley, P.M., Katz, L.E.: Sorption phenomena in subsurface systems: concepts, models and effects on contaminant fate and transport. Water Res. 25(5), 499-528 (1991)

26. Yu, S.C.T.: Transport and fate of chlorinated hydrocarbons in the vadose zone-a literature review with discussions on regulatory implications. J. Soil Contam. 4(1), 25-56 (1995) 